\title{
El sujeto eclipsado en la poesía de Diego Maquieira
}

\author{
The eclipsed subject in the poetry of Diego Maquieira
}

\author{
Ana María Riveros Soto \\ Pontificia Universidad Católica de Valparaíso, Instituto de Literatura y Ciencias del Lenguaje, \\ Viña del Mar, Chile. Correo electrónico: ana.riveros@ucv.cl
}

\begin{abstract}
El presente estudio tiene como objetivo principal efectuar una lectura centrada en la configuración del sujeto poético presente en la obra Diego Maquieira, específicamente en el poemario La Tirana, de 1983, y en la plaquette Los Sea-Harrier en el firmamento de eclipses. Poemas de Anticipo, editada en 1986, bajo la comprensión del mismo como "sujeto eclipsado", en tanto cada una de las entidades presentes constituyen figuras en permanente estado de interposición y superposición, lo que da origen a dinámicas de elisión y permuta de identidades que posibilitan, como único mecanismo de reposición del yo, la disolución fronteriza entre ambas entidades: sujeto opresor y sujeto oprimido. Lo anterior, considerando las articulaciones existentes entre la configuración del yo y la lengua, ésta última como entidad que somete -tiraniza- y se subordina, a la vez, en el marco del proceso de fractura, traslación y desintegración del sujeto poético.
\end{abstract}

Palabras clave: sujeto, eclipse, transposición, identidad, lengua, poder

The main purpose of the following study is to undertake a reading centered in the configuration of the poetic subject that is present in Diego Maquieira's work, specifically in 1983 collection of poems entitled La Tirana, and in the plaquette Los Sea-Harrier en el firmamento de eclipses. Poemas de Anticipo, edited in 1986, understanding the poetic subject as an "eclipsed subject", since each one of the present entities constitute figures in permanent state of interposition and superposition. This originates dynamics of elision and identity exchanges that enable -as the only mechanism of replacement of the self- the borderline dissolution between both entities: oppressor subject and oppressed subject. The above, considering the existing articulations between the configuration of the self and the language, the latter as an entity that submits tyrannizes- and subordinates, at the same time, in the framework of the fracture, translation and disintegration of the poetic subject.

Key words: subject, eclipse, transposition, identity, language, power 


\section{INTRODUCCIÓN}

La lectura en torno al poemario La Tirana (1983) y la plaquette Los Sea-Harrier en el firmamento de eclipses. Poemas de Anticipo (1986) ${ }^{1}$, nos permite postular la noción de un 'sujeto eclipsado', puesto que la entidad poética en ellos presente da cuenta de un proceso permanente de interposición y superposición entre las dos figuras opuestas que lo componen: el opresor y el oprimido, a partir de las cuales se generan inagotables dinámicas de reconocimiento, unión y supresión, lo que posibilita, en consecuencia, la desarticulación o desintegración en el texto de las entidades subjetivas y los supuestos sobre los cuales éstas se sostienen. En La Tirana, el sujeto opresor acontece representado por la figura de Velásquez -Diego Rodríguez de Silva y Velázquez-, y el sujeto oprimido, por la misma Tirana. Por su parte, en Los Sea-Harrier en el firmamento de eclipses, la entidad dominante se manifiesta a través del bando de los Milenaristas, mientras que los Harrier representan el bando de los sujetos dispuestos bajo opresión. Esta última relación es referida en el texto en términos de una contienda permanente entre los milenaristas y la 'barbarie', tal como ha expuesto la crítica en torno a la edición posterior de 1993 (Peralta 2006).

El término 'eclipse', circunscrito al campo de la astronomía, se define como "ocultación transitoria total o parcial de un astro por interposición de otro cuerpo celeste" (RAE 2003: en línea). En el marco de ambos poemarios, cada uno de los sujetos tiende a interponerse o superponerse ante el otro con el fin de subsumir o aprehenderlo, someterlo, generando, no obstante, un permanente vínculo de interdependencia a partir del cual el sujeto oprimido es opresor, y viceversa. En las obras de Maquieira se produce dicha interconexión entre los sujetos, proceso mediante el cual se genera la permuta de sus respectivas propiedades, puesto que cada uno se transforma a la vez en el otro, se somete y comporta según los códigos del otro, como único mecanismo de sobrevivencia ante la fragmentación y la precariedad que constituye en sí mismo. Lo anterior se conecta con el origen propio del término 'sujeto', proviente del latín subiectus, participio de subiicěre que significa "poner debajo, someter" (RAE 2003: en línea), y cuyo sentido se encuentra asociado etimológicamente a la idea de sumisión, subordinación y sujeción, vale decir, la comprensión del sujeto como una entidad determinada permanentemente por una acción externa a la cual debe entregarse y someterse (Krysinski 1993: 270).

\section{La Tirana: Transposición De SUJETOS En DECADENCia}

La Tirana, como sujeto femenino y entidad oprimida, da cuenta en el texto de los caracteres propios del llamado sujeto posmoderno, a razón de constituir en sí misma una entidad fragmentaria, escindida y degradada. En el marco de la posmodernidad,

Si bien la obra poética completa de Diego Maquieira consta, en estricto rigor, de cinco poemarios de breve extensión, la crítica literaria habla por lo general sólo de cuatro textos, debido a que la cuarta publicación, la plaquette Los Sea-Harrier en el firmamento de eclipses. Poemas de Anticipo constituye, según el mismo poeta ha señalado, una publicación menor sujeta a modificación, en tanto el formato de plaquette no corresponde a la presentación de un texto definitivo, sino al de un anticipo -tal como lo indica su nombre- de algunos de los poemas que formarán más tarde parte del poemario Los Sea Harrier de 1993, edición que incluye, con algunos ajustes formales, la totalidad de los textos de 1986, a excepción del poema "Proclamación de la Independencia Americana a borde de nuestro portaaviones Citta Felice por Lope de Aguirre Peregrino", el que fue completamente suprimido en la edición definitiva de 1993. 
Lyotard (Cit. en Roa 1995: 46) apunta que las fronteras que distinguen con claridad la división entre sujeto y objeto se deshacen, la escisión se desvanece y con ello la figura del yo: la realidad se vuelve inestable, por lo que no es posible establecer premisas certeras en torno a la concepción del yo. En la obra de Maquieira el sujeto que acontece acentúa paulatinamente su desintegración, hasta alcanzar en los últimos versos un estado de evidente agonía, de un sujeto sostenido apenas por el hilo de una voz mediante la cual intenta desesperadamente asirse de aquel otro yo -el opresor-, el único que puede mantenerle con vida: "Diego para / Para Diego / Para Diego / ¿Puedes parar Diego? (...) Tengo miedo / Tengo miedo, Diego / Diego, se me va la cabeza / No hay duda alguna (...) raja, estoy volviendo loca, Raja / contéstame / me estoy volviendo loca" (Maquieira 2003: 82).

Una de las particularidades del sujeto en La Tirana es su pertenencia a una decaída aristocracia chilena, debilitada y empobrecida, representada a través del personaje femenino: "Y si bien vengo de una familia muy conocida / Y si es cierto que me sacaron por la cara / y que los que están afuera me destrozarán / Aún soy la vieja que se los tiró a todos / Aún soy de una ordinariez feroz" (Maquieira 2003: 25). En este contexto, emergen en el poemario aquellos espacios urbanos, públicos y privados, en los cuales los integrantes de esta laya suelen reunirse: la iglesia, el salón -el Salón Rojo del Palacio de La Moneda-, el Teatro Municipal, el restaurante Torres, el Hotel Valdivia y el Cine Marconi, como íconos en decadencia de la socialité santiaguina de mediados de siglo: "Para nosotros el Marconi se cae a pedazos / y desde cientos de butacas manchadas / se levantan tus infieles / como la antena de un monstruo" (Maquieira 2003: 55).

Todos estos espacios son semantizados como lugares de encierro, locura y anquilosamiento de tiempos gloriosos y remotos (Brito 1994: 105), zonas claustrofóbicas mediante las cuales se representa el encierro de una lengua encarcelada bajo la voz del opresor (Galindo 2005), y de un sujeto en iguales condiciones. La ciudad se constituye de este modo como espacio de encierro, erotismo y demencia en el cual se transgreden los valores, normas y convenciones sociales del 'buen vivir'. Es el espacio de la "baja prostitución” en palabras de Bataille, "la prostitución moderna", la zona de "desmoronamiento" social, humano, moral (Cit. en Harris 2003: 109); carácter que también atribuye Berman (1997: 161) al espacio urbano, comprendido como enclave en el cual el hombre, abolido por la modernidad, pierde dominio, y en el cual se generan instancias de desencuentros consigo mismo y los otros - a diferencia de lo que presupone la ilusión de la modernidad y el deslumbre de la vida burguesa-, dando paso a la materialización de su propia decadencia.

Este descenso, vinculado a la proyección del entorno aristócrata capitalino, se reproduce con claridad a través de la figura del español Diego de Velázquez, amante de La Tirana, quien acontece en el poemario con significativas marcas de una degradación igualmente encarnada por el personaje femenino: "Pero cómo fuiste a caer en eso / quién sabe qué degradada e innoble vida / debes estar viviendo / qué horribles deben haber sido tus rodeos / antes de ser fotografiado / qué perdida debe andar tu alma Velásquez" (Maquieira 2003: 75). La entidad dominante -Velázquez- es, al igual que La Tirana, un sujeto en ruinas que emerge en el poema como uno de los escasos sobrevivientes de un imperio - la aristocracia chilena- absolutamente derruido. Al respecto, Brito sostiene que en La Tirana se presenta una "acerba autocrítica" en torno a la vida de la nobleza -la "gran vida"- y sus salones, en tanto éstos se sustentan 
exclusivamente en la mediocridad, la vanidad, el hurto y la violación de los derechos y la moral. En la obra de Maquieira se materializa la "destrucción de los íconos más queridos de la sociedad chilena (...) de la clase alta" (Brito 1985: 45), y se agudiza su respectivo deterioro mediante los actos de violencia y degradación reproducidos por los mismos integrantes de esta clase. Tal deterioro deriva, según la autora, en la pérdida final del lugar, del locus y, en consecuencia, de la identidad, del cuerpo y del lenguaje del sujeto: "Qué gran final es morirse, Velásquez / pero qué triste / y la verdad es que no queda nada, nada" (Maquieira 2003: 75).

Un primer elemento de la transposición producida entre ambos sujetos está determinado por el deterioro y el descenso que padecen, a pesar de su filiación con las esferas altas del poder, de índole social en La Tirana; de carácter socio-político y religioso en Velásquez. El sujeto femenino es representado en pleno proceso de decadencia, ante lo cual intenta resistir por medio de la figura de Velásquez, sujeto opresor en deterioro que ejecuta el mismo movimiento de la entidad femenina, en pos también de su propia supervivencia. Al respecto, la crítica ha apuntado variados significados en torno al apelativo 'Tirana'.

En primera instancia, se hace referencia a la leyenda de la india cuzqueña que en los tiempos de Diego de Almagro fue conocida por los castellanos como 'La Tirana del Tamarugal', debido a su despotismo e inclemencia ante los españoles que, con la ayuda de otros indios rebelados, tomaba prisioneros en venganza por la muerte de su padre, un sacerdote inca. En medio de esta lucha, la joven se enamora del portugués Vasco de Almeyda, a quien había tomado cautivo y condenado a muerte, pero que posteriormente libera para huir con él, previa conversión a la fe católica por medio del bautismo. Ambos finalmente fueron asesinados por los indígenas a causa de la traición cometida (Emmerich 2004: 10). En este contexto, el nombre se asocia asimismo con el de la festividad religiosa que se celebra en el Norte Grande del país, la 'Fiesta de la Virgen del Carmen de La Tirana', que acontece como un evento sincrético en el cual se articulan, mezclan y fusionan códigos mestizos, indígenas y católicos; por un lado, como signo de la religiosidad marginal -virgen negra, erótica y oscura- (Brito 1994: 95); y por otro, como un evento que representa la degradación del hombre, en tanto en él se reproduce el encuentro de la virgen con el diablo, el ángel caído de la rebelión -al igual que la india cuzqueña-, lo que significa el desplome de un reino, la expulsión del paraíso y el encuentro del hombre con sus instintos más bajos: "la rebelión, la transgresión, es castigada con la degradación al estado animal -negación de la humanidad, del alma- suplantada por la caída, negada por el desmoronamiento que, a su vez, degrada el erotismo en su conjunto arrojándole 'la luz del mal'" (Harris 2003: 112).

Coincidimos con Galindo (2003: 105) al considerar que la nominación de $L a$ Tirana remite al lector, por otra parte, a la figura autoritaria de Augusto Pinochet durante la dictadura militar en Chile; lectura que, sin embargo, el mismo Maquieira ha desestimado al reconocer una connotación del concepto asociada más bien a "la "tiranía" del amor carnal"2". La asociación del término con el chilenismo tirar,

\footnotetext{
En sesiones de entrevistas efectuadas durante el año 2005, Diego Maquieira ha señalado a propósito del nombre $L a$ Tirana: "Mucha gente ha visto a la Tirana como 'el Tirano', y como coincide la publicación con la época de Pinochet, dicen que es el reverso, pero no es así. (...) No, me conecté más con la idea de la Tirana como tiranización, y con tirar, sexo. La satrapía, la esclavitud del sexo, la tiranía del sexo también. Tiene que ver con la noción de tirar, que es muy local, tirar" (Cit. en Hidalgo y Hopenhayn 2008: 53-54).
} 
mediante el cual se expresa coloquialmente el encuentro erótico entre dos sujetos, ha sido igualmente referida por la crítica, como asimismo la acepción de La Tirana como metáfora de la Quintrala, Catalina de los Ríos y Lisperguer, aquella aristócrata santiaguina de la época colonial que, al igual que La Tirana, "se los tiró a todos", y asesinó a cada uno de sus amantes (Galindo 2003: 106).

A nuestro parecer, la nominación da cuenta del mismo modo de un sujeto en femenino, de una 'tirana' que en concreto es presa de la tiranía del otro, por lo que no ejerce su poder como en tiempos pasados, sino que, por el contrario, es sometida al amor y el desprecio -la tiranía del amor y la carne- de Diego de Velázquez, quien finalmente la abandona y reemplaza por Alessandra Mussolini -nombre proveniente de la nieta del Duce-. Al respecto, Brito alude a la figura femenina como metáfora del cuerpo débil, abusado y explotado por otro, como el espacio del "hueco", la herida del inconsciente latinoamericano en la cual confluyen las imágenes de la virgen, la madre, la amante, la vieja "tiradora", la prostituta: "Hueco que actúa como producción textual, texto y metáfora de otro texto: Chile, con un lado inexplorado y, por lo tanto, 'virgen', 'puta', en cuanto va a la venta; madre, en cuanto generadora de hijos, india, por cuanto acusa sobre esa lengua, sobre su hueco, su lado oscuro y desbordado" (Brito 1994: 99).

Asimismo, la referencia a una tirana 'en femenino' permite la comprensión de un sujeto a la inversa y desmoronado, una 'tirana' que no lo es ya, y que, por el contrario, es víctima de la dominación por parte del otro. Es el sujeto femenino que simboliza la historia de América Latina y de las etnias indígenas explotadas, abusadas por el conquistador español, encarnadas en el poemario por Velázquez y la Inquisición: "La elipsis barroca hace más patente el hiato en que América Latina, hija de España y de las etnias indias, tiraniza al lenguaje por medio de otra gran tiranía provocada por el mestizaje: un forzamiento del cuerpo, que penetrado y fecundado por Otro, no su par, sino su dominador" (Brito 1994: 107-108). En este contexto, tiene lugar la metáfora de América Latina como cuerpo débil y femenino, sometido y violentado por parte de otro cuerpo dominante y masculino: España y los conquistadores. Dussel señala que el ego violento y guerrero del conquistador constituye además un "ego fálico", representante del poder masculino y europeo por sobre las tierras e indígenas americanas:

La violencia erótica vino simplemente a mostrar la "colonización" del mundo de la vida indígena (...). Se trata del cumplimiento de una voluptuosidad frecuentemente sádica, donde la relación erótica es igualmente de dominio del Otro (de la india). Sexualidad puramente masculina, opresora, alienante, injusta. Se "coloniza" la sexualidad india, se vulnera la erótica hispánica, se instaura la doble moral del machismo: dominación sexual de la india y respeto puramente aparente de la mujer española (Dussel 1992: 72-73).

Por su parte, Maquieira enfatiza la voz femenina que constituye el hablante lírico del texto desde la perspectiva de la matriz, del origen, como espacio auténtico en el cual se resguarda al hombre en su condición primigenia. Desde esta perspectiva, el autor plantea la lectura de La Tirana como el intento permanente del sujeto por conservar su propia dignidad, en una permanente lucha por sobrevivir y sostenerse a sí mismo en medio de la desintegración que encarna. Es el último impulso del sujeto por recuperar su identidad, a través del retorno hacia la madre, la Virgen María, la matriz (Cit. en Hidalgo y Hopenhayn 2008: 54-55), tentativa sobre la cual se fundan 
los movimientos eclipsados y de transposición que ejerce con el propósito de no perecer en medio del desastre que él mismo representa.

Es así como la interposición permanente entre ambos, dominante y dominado, constituye un juego de identificaciones, de fusión o cruce de propiedades que se levanta como único mecanismo de supervivencia, el que se dispone a partir de la dependencia o sujeción irrestricta del yo respecto del otro. La deconstrucción derridiana postula la disolución de las fronteras dispuestas entre fenómenos contrarios, colocando el énfasis en los puntos de conexión presentes entre ambos, lo que en el caso de Maquieira, opera a nivel de los mecanismos de supervivencia e interdependencia que activan mutuamente las figuras de Velásquez y La Tirana, y por medio de las cuales se desarticula la distinción entre ambas identidades.

A través del método deconstructivista, y específicamente de la noción de differance -diferencia-, Derrida (Cit. en Culler 1992: 81) desarrolla un pensamiento a través del cual se intenta desmontar el concepto trascendental de sujeto y la lógica de la identidad, lo que alcanza, asimismo, la materia de la lengua, en función de la estructura logocéntrica que la conforma. Ello tiene lugar mediante un proceso de corrosión del sistema lingüístico -como representante a su vez de otros sistemas extralingüísticos- efectuado desde el interior de sus propios dominios y, por consiguiente, el desmantelamiento de las oposiciones binarias y jerárquicas sobre las que éste se sostiene.

En relación a Maquieira, la crítica ha concebido el término "tirana" como metáfora del discurso, de la lengua: por una parte, la lengua indígena y mestiza como lengua "minada y perforada"; y por otra, la lengua del conquistador, vale decir, la verdadera tirana. Brito señala que La Tirana representa la tiranía de la lengua española, la que se superpone por sobre las lenguas aborígenes, generando su imposición e incluso su anulación respecto de esta última. En la obra de Maquieira, La Tirana es precisamente heredera de una lengua extranjera, fundadora y aristócrata, a través de la cual se ha explotado e invalidado al otro. Se genera, de este modo, el encuentro y la tensión entre dos discursos - dos lenguas-, de las cuales la lengua violentada "soporta, retiene y reproduce las represiones y los huecos en torno de los cuales se estructura el inconsciente" (Brito 1994: 99), una lengua que, en definitiva, logra ser sometida y encarcelada -como la tirana cuzqueña- por aquella otra dominante, hegemónica; tensión que genera una especie de "lengua híbrida" (Donoso 2007: 7), "anómala y mestiza" (Donoso 2007: 7), injertada, en la cual confluyen las voces de ambos sujetos -y otros- en razón de la permutación de sus respectivas identidades.

En torno al sujeto opresor, Diego de Velázquez, se establecen, igualmente, algunas significaciones relevantes. En primer lugar, su relación respecto al personaje histórico, Diego Rodríguez de Silva y Velázquez -su nombre completo tal y como versa al comienzo del poemario-, máximo exponente de la pintura barroca española del siglo XVII, y pintor de la corte de Felipe IV, es quien figura en el texto de Maquieira como el principal amante de La Tirana, en rigor ex-amante que la ha dejado en un doloroso estado de abandono. A partir de la profunda añoranza que en ella produce, Velázquez ejerce la acción de "tiranizar" al sujeto femenino a lo largo de todo el texto: "Porque como ya sé que me has abandonado / y que piensas robarme toda la plata / No te quedes con todo, no seas tan duro / déjame por lo menos tu vanidad / (...) El amor que yo llevo adentro es terrible / es como arrasar vientos y conmover despojos" (Maquieira 2003: 27).

Es así como la entidad femenina no es la que subyuga, sino, por el contrario, es quien padece los efectos de la indiferencia del sujeto masculino. En este contexto, 
Velázquez representa la figura del conquistador español: en La Tirana, es el colonizador quien encarna el proceso de imposición europea y española en América Latina por sobre el sujeto femenino violentado e indígena, al cual "se están pisando desde 1492” (Maquieira 2003: 26), y en definitiva, el sistema hegemónico -España, el Imperio, la Inquisición- y su respectiva traición aplicada al pueblo subyugado.

Por otro lado, la crítica ha enfatizado el significado de Velázquez como autor de Las Meninas (1656), en tanto la obra permite remarcar la noción del texto vuelto sobre sí mismo, vale decir, el pintor que se pinta a sí mismo o el espectador que se refleja en el mismo texto, lo que permite vincular al mismo autor empírico del poemario, Maquieira, también de nombre Diego (Galindo 2003: 107). Precisamente, la noción de "crisis de representación" que se hace presente en el cuadro, en tanto se diluyen los límites entre el observador -el espectador- y el objeto observado -el mismo cuadro-, nos permite articular la relación entre reflejos, dobles y reversos presentes entre el sujeto opresor y el sujeto oprimido. En cuanto a Las Meninas, Brito ha señalado que su referencia indirecta en La Tirana permite el cuestionamiento en torno a quiénes son efectivamente los sujetos que operan en el texto, de modo de generar finalmente "significados vacíos de un significante quebrado, suspendido, abierto a la cultura y el pensamiento" (1994: 100). Se pierden, así, las certezas respecto de las identidades que sostienen -o desestabilizan- el texto, quién es el sujeto que pinta, quiénes son los sujetos pintados, cuáles son las identidades que se arman y desarman en el texto.

Foucault relativiza, justamente, los espacios y entidades que forman parte del acto de representación, de modo de enfatizar la inestabilidad que ésta sugiere, vale decir, los objetos de representación son el uno y el otro a la vez: el pintor, el cuadro, el objeto pintado. Las entidades e identidades se superponen, interfieren, aparecen, desaparecen en un juego permanente de espejeos y apariencias, cuyo núcleo está dado, precisamente, por el espejo que se visualiza al interior del cuadro, en el cual se reflejan los modelos situados paradojalmente en su exterior, el rey Felipe IV y su esposa Mariana. De este modo, Foucault expone en torno al espacio de la representación:

(...); en este lugar preciso, aunque indiferente, el contemplador y el contemplado se intercambian sin cesar. Ninguna mirada es estable o, mejor dicho, en el surco neutro de la mirada que traspasa perpendicularmente la tela, el sujeto y el objeto, el espectador y el modelo, cambian su papel hasta el infinito. La gran tela (...) obstinadamente invisible, impide que la relación de las miradas llegue nunca a localizarse ni establecerse definitivamente. (...) Por el hecho de que no vemos más que este revés, no sabemos ni quiénes somos ni lo que hacemos. ¿Vemos o nos ven? En realidad el pintor fija un lugar que no cesa de cambiar de un momento a otro: cambia de contenido, de forma, de rostro, de identidad (2006: 14-15).

El sujeto poético en la obra de Maquieira constituye una identidad móvil, movediza, que se trastoca o interpone con la de su reverso: sujeto opresor y sujeto oprimido se interceptan, superponen, permutan propiedades y eclipsan el uno al otro, como motor y consecuencia a la vez de la desestabilización que padecen. Ambos sujetos se funden y confunden, se enmascaran, son uno y otro simultáneamente en ambos poemarios: Velázquez y Los Milenaristas como entidades dominantes; La Tirana y Los Sea-Harrier como entidades sometidas, generándose de este modo un mecanismo de transferencia de propiedades o huellas que permiten reconocerlos como tales. En el caso del yo 
oprimido, es la degradación, la decadencia, la anulación; en el caso del yo opresor, es la dependencia, la filiación necesaria respecto de la otredad a la cual dominar.

En este contexto, Paul Ricoeur reconoce que el núcleo de la subjetividad está constituido por la ipseidad, en tanto afirma que aquella sólo puede ser percibida a través de la presencia de un "otro", vale decir, de una alteridad que pasa a ser parte constitutiva del sujeto en sí mismo, y mediante la cual se posibilita la configuración de su identidad y la comprensión de ésta como idem e ipse a la vez; en el caso de Maquieira, las dos caras de la tiranía: opresor y oprimido. De este modo, se concibe al sujeto en su relación directa con el otro, puesto que lo otro es parte constituida del yo sin dejar de constituir la alteridad, la diferencia respecto justamente de la ipseidad, del núcleo de subjetividad de sí mismo: "la ipseidad del sí mismo implica la alteridad en un grado tan íntimo que no se puede pensar en una sin la otra, que una pasa más bien por la otra, como se diría en el lenguaje hegeliano" (Ricoeur 2003: XIV).

Es así como en La Tirana, la entidad femenina se presenta oculta permanentemente tras el velo de aquél que la somete y esclaviza: por un lado, como mujer de buena familia, culta, aristócrata; por otro, su propio nombre y la desfachatez -o soberbiapara dar cuenta de sus atributos: "Yo, La Tirana, rica y famosa / la Greta Garbo del cine chileno / pero muy culta y calentona (...) Aún soy la vieja que se los tiró a todos / aún soy de una ordinariez feroz" (Maquieira 2003: 25). Sin embargo, el despotismo manifiesto por el sujeto femenino se tuerce prontamente hacia sí mismo, puesto que es ella quien padece la tiranía del amor -y desamor-. A lo largo del texto, se va acentuando el nivel de decadencia y degradación del sujeto, el que alcanza hacia el cierre del poemario un agudo estado de delirio, dependencia y anulación del yo: "Que gran final es morirse, Velásquez / Tengo una tristeza de cadena perpetua / Soy la que viene de arriba abajo / Soy la que más cae desde más alto / Pero soy la que se viene abajo entera / No la que está muriendo a pedazos" (Maquieira 2003: 79).

La Tirana opera en el texto como un sujeto bisagra, en tanto tiende a travestirse en función de este doble rostro: por un lado, el sujeto oprimido y, por ende, degradado, marginal; y por otro, el sujeto asociado al opresor o enmascarado como tal -"pintarrajeado" (Brito 1994: 107)-, puesto que, al igual que Velázquez, proviene de un origen aristocrático. Sin embargo, en La Tirana ambas entidades -opresor y oprimido- son figuraciones escindidas, fracturadas, incompletas, al igual que la india cuzqueña situada en el espacio del margen, quien cae por amor en el umbral que la sitúa en el espacio opuesto, al cual no pertenece. De este modo, La Tirana se transforma en el simulacro del sujeto opresor, se transfigura en él como vía de supervivencia a través de la cual intenta sujetarse -volverse 'sujeto'-, haciendo uso de su propia voz, tirana y despótica: "Que sepa cada gallina nacida aquí / que el cielo se va a abrir / y ya no lo van a ver más azul / sino que va a quedar un medio hoyo / y desdichado del que se acerque" (Maquieira 2003: 62). La Tirana desarrolla, a su vez, el vínculo filial con el sujeto español -“tirarse a Velázquez”-, con el fin de alcanzar la posición de un "yo" mediante el encuentro amoroso entre ambas entidades representación máxima del eclipse-:

Yo me tiraba a Velázquez en su Cristo

yo la madre del demonio español

llorando de negro sobre mis vestidos de lágrimas

Se lo soltaba yo mi pelo, mis pinturas 
que tenían más brillo en su cara

Allí en la gran cama se me paraba sola

la media vida, la vida demente de Dios

(...)

Que me tiraba a Velázquez con el dolor de mi alma

me han sacado el cielo de la luz

sólo quedan mis brazos afuera en el prado (Maquieira 2003: 70).

El encuentro erótico constituye el instante en el cual se genera el reconocimiento del yo -La Tirana- en el otro -Velázquez-, vale decir, el intento por reflejarse en este último y confundirse con el sujeto dominante, ocultarse -enmascararse- bajo su rostro, el que, asimismo, concede vida, pues Velázquez la "pinta", la funda en una imagen sin transfondo, cual simulacro de su misma representación: "pintada por Diego Rodríguez de Silva y Velázquez / Mi cuerpo es una sábana sobre otra sábana / el largo de mis uñas del largo de mis dedos / y mi cara de Dios en la cara de Dios / en su hoyo maquillado la cruz de luz" (Maquieira 2003: 26). En el contexto de Las Meninas, es la traición del sujeto opresor, traducida en la ilusión del espejo -“el espejo de Velásquez" (Maquieira 2003: 36)-, su artificio, su imagen dispuesta en reverso y, por consiguiente, el desesperado deseo de la entidad dominada por acontecer en la tela, aun cuando sea a retazos del mismo yo: "mi pelo atascado en la cruz del rosario / me volé la luz dándome de lleno / en el espejo blanco sobre las sábanas de mi cama" (Maquieira 2003: 68).

\section{Los Sea-Harrier: Transposición de Sujetos en PUgna}

En el caso de Los Sea-Harrier en el firmamento de eclipses, el sujeto oprimido asume, del mismo modo, la voz y acción del opresor, en tanto los Harrier actúan con la misma o mayor violencia y crueldad que la planificada y ejercida por los Milenaristas: “-La centuria tiene que empezar a escoger / ya pasó el tiempo para los epicúreos / y hedonistas, para esos vagos y ladrones / y debemos hacer que desaparezcan / (...) La centuria comienza y vamos a poner orden / pero los Harrier no lo ven de ese modo" (Maquieira 1986: s/p)3 . El ánimo despótico del bando opresor se transfiere hacia el oprimido, los Harrier, generando el eclipse entre ambas entidades, la desaparición de la voz oprimida y el levantamiento de la voz del opresor, pero en este caso no como mecanismo de anulación del primero, sino más bien como acto de resistencia ante la amenaza de exterminio efectuada por el segundo. Los Harrier se transforman en el sujeto opresor, reproduciendo el violento actuar de este último: "Les enviamos unos Harrier con bombas de racimo / y unos cuadros de exposición de Mussorgsky / como regalo previo a la masacre, al año nuevo / que les íbamos a dar a nuestros hermanos de luz, / aunque la luz se la íbamos a llenar de humo" (Maquieira 1986: s/p).

Si bien el accionar de los Harrier constituye una lucha y un acto de liberación en contra de la imposición ejercida por la entidad dominante, sus movimientos emancipadores se trastocan y transfiguran en acciones igualmente déspotas y tiranas, a partir de las cuales se pretende destituir un régimen totalitario para constituir, en

La plaquette en la cual se publica el texto en 1986 no presenta páginas numeradas, por lo que en lo sucesivo las citas que efectuemos a la presente obra no contendrán dicha información. 
definitiva, otra dictadura. Es precisamente lo que se manifiesta en el único poema del anticipo de 1986 suprimido en la edición final de 1993: "Proclamación de la Independencia Americana a borde de nuestro portaaviones Citta Felice por Lope de Aguirre Peregrino". Este texto corresponde a un fragmento de la Carta al Rey Felipe II del conquistador español Lope de Aguirre apodado "El Tirano", supresión que opera como metáfora de la elisión de la identidad del sujeto oprimido, su absorción y su sustitución por la hegemonía, la voz del poder:

\begin{abstract}
"yo maté al
Nuevo Rey, y al capitán de su guardia, y al teniente general, y a cuatro capitanes, y a su mayordomo mayor, y a su capellán, clérigo de misa, y a una mujer de la liga contra mí, y un Comendador de Rodas y a un Almirante, y a dos alféreces, y a otros cinco o seis aliados suyos; y con intención de llevar la guerra adelante y morir en ella... nombré de nuevo capitanes y sargento mayor, y luego me quisieron matar y yo los ahorqué a todos..." (Maquieira 1986: s/p).
\end{abstract}

La degradación del sujeto en el caso de Los Sea-Harrier ... se asocia, más que a la desintegración de sí mismo, a un movimiento de descenso moral, en tanto el abuso de poder y la matanza por ellos generada en contra del sistema opresor tiene sus bases en la vinculación del sujeto con la dimensión del mal, con aspectos de orden demoníaco tal como se visualiza en el sincretismo religioso presente en la fiesta de La Tirana, contexto en el cual se reproduce el encuentro entre la virgen y el demonio (Harris 2003: 112). En el caso de Los Sea-Harries... es posible visualizar dicha relación de modo explícito, según lo expuesto en los siguientes versos:

Después de la matanza post juicio final

Arriba de nuestros Harrier

De la recepción de la posma milenarista

Y del colapso de las religiones

Me había metido a nuestro ayuno en el mar

A nuestra larga iniciación con el Demonio

Que nos sacaba de la cueva del mono caído

Y nos llevaba en brazos hacia la luz

Después de haber dejado sollozos a los milenaristas

columpiándolos por un rato sobre los decorados

enfriamos los Harrier rumbo a guardarlos

a nuestro lujoso paquebote en medio del mar

El Atolón Luciferino con sus novecientos

metros redondos de telones

abrían los ojos a la belleza (Maquieira 1986: s/p).

La transposición de sujetos se efectúa por medio del posicionamiento del yo oprimido en los espacios del opresor y de las técnicas represivas, las que no 
son dignas de los hombres de bien, sino, por el contrario, se asocian a acciones maléficas, perniciosas, perjudiciales. Los Harrier, al parecer, no tienen otra forma de autodefenderse y hacer frente a los propósitos y políticas de eliminación dispuestas por los Milenaristas. Sin embargo, en su intento por sostenerse ante los otros eliminando y destruyendo a los otros- no hacen otra cosa que desmoronarse en sí mismos, decaer, autodesintegrarse paulatinamente, tal como sucede con el yo opresor.

Lo anterior se manifiesta con la muerte y sepultura, "encielada" (Schopf 1987: 15) del líder de los Harrier, Phillip Rastelli -nombre proveniente de la mafia neoyorkina-, quien es muerto en uno de los enfrentamientos contra los Milenaristas. El poemario concluye con el "Sermón dado a Phillip Rastelli antes de morir", situación mediante la cual se da cuenta de la anulación final -y fatal- de la entidad oprimida al ocupar el lugar del opresor. Es el deceso y la autodestrucción del sujeto al asumir los códigos del otro, a través de los cuales se atenta contra sí mismo y la propia naturaleza humana: "Estamos aquí reunidos / Ante la vista de Dios / Y de toda su gloria / Para que descanse Phillip Rastelli / (...) / Mataba demasiado / Era codicioso como pocos / Tal vez no respetó a nadie / Pero era impecable en eso / Ricos y pobres / Recibieron sus atentados / (...) / Ahora la sangre que él venció y amó / Lo ha cubierto finalmente" (Maquieira 1986: s/p) .

Respecto al sujeto opresor, tanto en Velázquez como en los Milenaristas, se hace expresa la decadencia per se que reside y se acentúa en cada uno de ellos, la que, no obstante, intenta disimularse en ambos poemarios mediante la apelación al discurso religioso y el catolicismo como instrumento de poder -la Inquisición-, y el doblez de la clase alta, como mecanismo distintivo de una raza humana superior, congruentes con principios fascistas e imperialistas: "Porque aquí te quitan la vida Velázquez / te sueltan el cuervo de la religión / (...) pero tú decías paraíso a las paredes / para no pasarte el mes solo en tu cama / con tus pantalones hechos bolsa / y con una imaginación de los manicomios" (Maquieira 2003: 31).

En La Tirana, la figura aparentemente sólida de Velázquez va decayendo poco a poco, dejando entrever la amenaza del yo como entidad, su desintegración y desmoronamiento a manos de sí mismo y de la aristocracia decadente a la cual pertenece, como también de los sujetos oprimidos que tienden a desestabilizarlo: "Velásquez, esto es el fin, volaron la sacristía / Te aconsejo que empaques luego tus cosas / te pongas tu cruz de Santiago y te largues / si aún piensas seguir con vida" (Maquieira 2003: 63).

\section{Religión y Lengua tiRana. Poder y traición en los Sujetos}

El discurso religioso opera en ambos poemarios como el pilar también en crisis al cual recurre el sujeto opresor, con el fin de sostenerse en medio de su propio desmoronamiento: "y porque no podías dejar que la cruz / se te fuera de las manos en ese momento" (Maquieira 2003: 30). Este discurso opera, sin embargo, como un montaje o representación tras cuya ilusión no hay otra cosa que la anulación efectiva del yo. Por consiguiente, el montaje del discurso evangelizador oficia como el único camino de los hombres de bien, en virtud de sus valores, la moral y las buenas

\footnotetext{
Este último poema de la plaquette corresponde a una transcripción modificada de uno de los diálogos del film $L a$ Balada de Cable Hogue (1970) de Sam Peckinpah, director norteamericano cuyo nombre figura igualmente en La Tirana como uno de los personajes que acontece en el poemario.
} 
costumbres de la clase aristocrática, en desmedro de la cosmovisión atea o indígena, concebida como barbarie. En ambos textos, es posible reconocer la mirada crítica en torno a la escisión civilización / barbarie postulada por Sarmiento (Cit. en FornetBetancourt 2000: 21), la que da cuenta de la falacia y el engaño levantados por todo proyecto imperialista y hegemónico, tras lo cual no hay más que vacío, falsedad y desintegración del sujeto, tanto a nivel del opresor como del oprimido, tal como expone Maquieira en el poema "El Gallinero":

\author{
Nos educaron para atrás padre \\ Bien preparados, sin imaginación \\ $(\ldots)$ \\ Nos metieron mucho Concilio de Trento \\ Mucho catecismo litúrgico \\ (...) \\ Y tanto le debíamos a los Reyes Católicos \\ Que acabamos con la tradición \\ Y nos quedamos sin sueños. \\ Nos quedamos pegados \\ Pero bien constituidos; \\ Matrimonios bien constituidos \\ Familias bien constituidas.
}

Y así, entonces, nos hicimos grandes:

Aristocracia sin monarquía

Burguesía sin aristocracia

Clase media sin burguesía

Pobres sin clase media

Y pueblo sin revolución (Maquieira 2003: 63).

En Los Sea-Harrier...la religión y, en particular, el catolicismo, se visualizan asociados al bando de los milenaristas, bajo el mismo carácter de entidad protectora, pero a su vez severamente castigadora, manifiesto de la Inquisición como acontece también con Velázquez, por medio de la cual se intenta purgar a la sociedad de sus pecados y de los infieles que no son dignos de la gracia y el perdón de Dios. Lo anterior se hace presente en la plaquette por medio de Ratz, líder de los Milenaristas, y cuyo nombre tiene su origen en la figura de Joseph Ratzinger, Prefecto de la "Congregación para la Doctrina de la Fe" durante la década de 1980, órgano colegiado del Vaticano que opera como sucesor de la antigua "Sagrada Congregación de la Romana y Universal Inquisición de la Iglesia Católica" $5 "$.

En Los Sea-Harrier..., los Milenaristas vinculan su accionar a la obra de Dios, situación que, al igual que en la interposición entre opresores y oprimidos, se traspone

\footnotetext{
En torno a la inclusión de Joseph Ratzinger, Pontífice de la Iglesia Católica entre los años 2005 y 2013, como Ratz, líder de los Milenaristas en la plaquette de 1986 y posteriormente en la edición de 1993, Diego Maquieira ha señalado lo siguiente: "Alguna vez oí, hace mucho tiempo, una declaración de Ratzinger cuando era Prefecto de la Congregación para la Doctrina de la Fe, y pensé 'este tipo es peligroso'. (...) De hecho, yo no intuía que Ratzinger iba a convertirse en Papa, sino que temía algo peor: la refundación de la Inquisición" (Cit. en Hidalgo y Hopenhayn 2008: 173).
} 
con el accionar del demonio, de la luz del mal: "Y el advenimiento: el Demonio va a venir a consolarnos / va a venir con su belleza infinita" (Maquieira 1986: s/p). La Iglesia, en ambos textos, opera como una entidad no benefactora, sino, por el contrario, como un organismo castigador, represivo, hasta siniestro, lo que permite la degradación de los sujetos resguardados bajo su alero: "Oh, qué feliz, alegre, chistoso, viejo Director de Circo / es Dios. / Te burlas de nosotros con tu sol, / que no nos calienta, / Nosotros temblamos de fiebre. / (...)/ Tú has ocultado tu promesa bajo la oscuridad de la muerte. / Actúas de mala fe, Oh Dios. / Tú no eres bueno. Tú no eres Dios" (Maquieira 2003: 54-55). De este modo, en Los Sea-Harrier ... se expone lo siguiente:

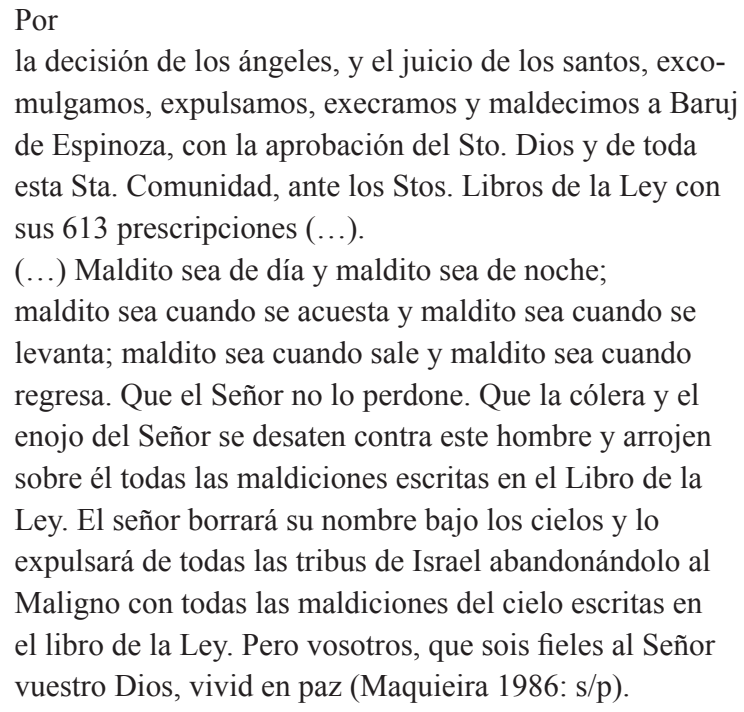

El segmento corresponde a una transcripción de un fragmento del decreto de excomunión otorgado en 1956 por la comunidad judía de Amsterdam a Baruch de Spinoza, filósofo racionalista y pensador religioso holandés, considerado el exponente moderno más completo del panteísmo. Es así como, en el contexto del poemario, los Harrier asumen la voz del sujeto opresor en tanto reproducen el juicio represor e inquisidor que debiese disponerse por parte del bando milenarista, generando, por ende, la transposición entre ambos sujetos. El castigo divino y eclesiástico constituye, en oposición a lo instaurado por la Iglesia, un acto de degradación humana en la cual el hombre, tanto el castigador como el sancionado -apresado- padecen el deterioro del yo. No obstante, dicho acto se concibe desde la perspectiva del represor como un acontecimiento ejemplar, digno de ser aplicado y presenciado por los otros, como medio de sermón y amenaza para el mismo pueblo. Es el espectáculo sancionador de la Inquisición, el montaje erigido con el fin de mantener a los súbditos bajo las disposiciones del sistema dominante, la Iglesia y el Imperio. No obstante, a través de este acto es posible la confluencia de ambos sujetos, verdugo y víctima y, en consecuencia, la transposición de ambas entidades. Al respecto, Foucault sostiene:

(...) el rito que "cerraba" el delito se hace sospechoso de mantener con él turbios parentescos: de igualarlo, sino de sobrepasarlo en salvajismo, de habituar a los 
espectadores a una ferocidad de las que se les quería apartar, de mostrarles la frecuencia de los delitos, de emparejar al verdugo con un criminal y a los jueces con unos asesinos, de invertir en el postrer momento los papeles, de hacer del suplicado un objeto de compasión o de admiración (2005: 16).

En la obra de Maquieira el espectáculo represor realizado en nombre de Dios y la Iglesia posibilita la transposición entre opresor y oprimido puesto que, siguiendo a Foucault, el sujeto opresor, al ocultarse tras el castigo, no hace otra cosa que exponerse en toda su crueldad y barbarie; mientras que al exhibir al yo reprendido, a la inversa, sólo se termina exponiendo al sujeto oprimido en toda su humanidad. Lo anterior evoca la figura de Jesucristo durante la Pasión, y el castigo público aplicado a un cuerpo que buscaba representar, por el contrario, la salvación de todos los hombres. En pos de la trasposición señalada, en Maquieira tiene lugar la identificación, no obstante, del cuerpo de Cristo con el cuerpo del delito, del pecado:

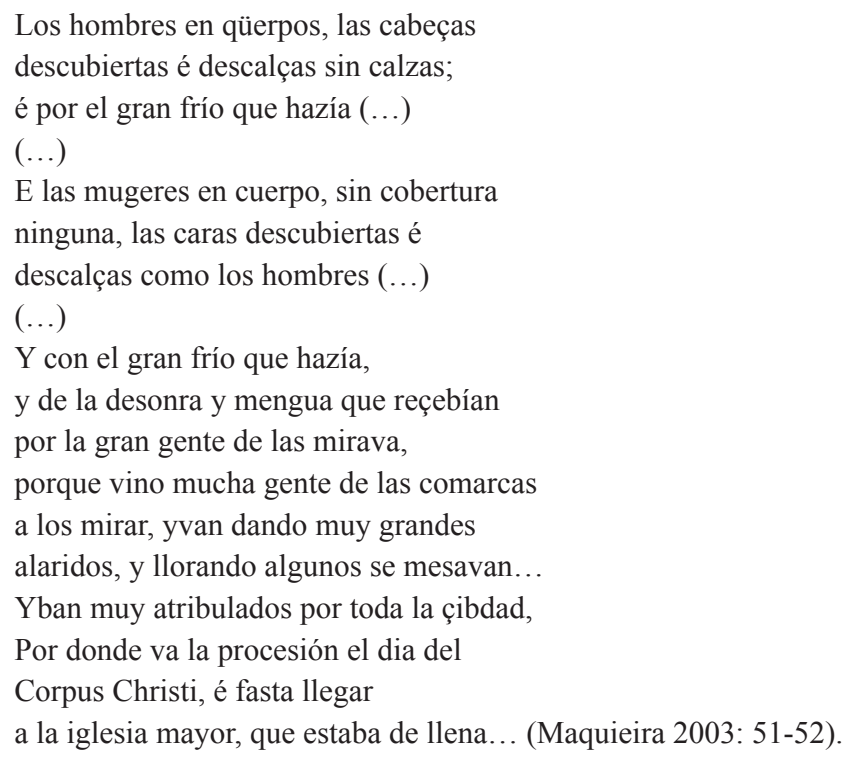

Desde el punto de vista de la degradación del sujeto opresor y del proceso de transferencia mediante el cual éste se vincula con el yo oprimido, en la obra de Maquieira la entidad dominante da cuenta de un mecanismo de sujeción y dependencia de él respecto de la entidad subordinada. Al respecto, Dussel (Cit. en Mignolo 2001: 57) sostiene que la periferia se sitúa necesariamente alrededor del centro, por lo que tiende a configurar a este último como tal. En otras palabras, el centro o la entidad dominante se impone en tanto tenga a su haber una entidad marginal, subordinada, sobre la cual ejercer su imposición. Es por ello que sólo es posible comprender la relación centro / periferia como un hecho de interdependencia sustancial entre ambas entidades opuestas. Por su parte, Gergen (1996: 27) apunta que las estructuras de poder, al instalarse como tales, gatillan la emergencia de su contraparte, vale decir, la aparición de un discurso dispuesto al margen, como espacialidad rigurosamente necesaria para la validación del centro y el sistema hegemónico. Los núcleos de 
inteligibilidad señalados por el autor, correspondientes a los sistemas de coherencias pertinentes a ciertos ámbitos de la realidad, a cada cultura, se articulan principalmente según la presencia e interrelación de ambos polos: centro y margen, y la necesaria existencia de uno para la concreción del otro. De este modo, en La Tirana se visualiza claramente la dependencia de Velázquez respecto de su sujeto oprimido, la misma Tirana -y no sólo en el sentido inverso-, puesto que la entidad dominante se nutre, alimenta o sostiene en función de la otra dominada: "Soy la última que va quedando / la última belleza, la Santa Escándalo / que te ilumina el alma de repente / y no por la luz que te hago llegar / sino por la vida tremenda que llevo" (Maquieira 2003: 79).

En el caso de ambos textos, la lengua opera como mecanismo efectivo de poder en tanto a través de ella, y particularmente del discurso religioso, moral y evangelizador erigido, se establecen las líneas de supremacía y subordinación que rigen por sobre los sujetos. La Tirana - quizás la verdadera tirana- es la lengua, la lengua hegemónica, española, que a través de sus recursos transgrede y modifica la realidad en función de su proyecto imperialista: "la lengua española es otra tirana de otras lenguas y culturas, cuya incorporación y fusión al español es innegable, pero que costó a estos grupos varios siglos de Inquisición" (Brito 1994: 100).

Gadamer (1992: 199) ha señalado que la experiencia del poder, como parte de los esquemas tradicionales de los distintos sistemas comunitarios, constituye un fenómeno que reside efectivamente en la materia del lenguaje. Todo encuentro con la realidad es articulado por medio de la comunicación lingüística. El poder, por tanto, se ajusta y manifiesta según las dimensiones verbales que lo conceptualicen mentalmente. Nociones como orden y servidumbre inciden en este moldeamiento y delimitan, por consiguiente, las distintas posiciones políticas e ideológicas existentes. La lengua constituye, según el autor, una estructura dicotómica y, como tal, preforma la noción de poder y su carácter bipartito con el cual éste actúa, vale decir, la escisión entre un yo opresor y un yo oprimido. Asimismo, Foucault establece el asentamiento del poder en el discurso, pues éste constituye el medio a través del cual opera y, a su vez, la materia de la cual forma parte:

(...) el discurso desempeña un papel dentro de un sistema estratégico en el que el poder está implicado y gracias al cual funciona. El poder no está, por tanto, al margen del discurso. El poder no es ni fuente ni origen del discurso. El poder es algo que opera a través del discurso, puesto que el discurso mismo es un elemento en un dispositivo estratégico de relaciones de poder (1999: 59).

En La Tirana la voz que enuncia es, en efecto, la lengua, la que se autodenomina "tremenda", "feroz" en función de sus posibilidades de dominación y opresión impuesta sobre los sujetos. A su vez, en razón de la transposición efectuada entre ambas subjetividades, la lengua paradojalmente es el discurso religioso y moral explotado, abusado por parte de la hegemonía con el fin de reducir y anular a la entidad marginal. De este modo, en la obra de Maquieira la lengua es tirana, pero también es abusada, violada, en tanto el hombre la ha obligado a operar como instrumento de la posición opresora y dictatorial. La misma lengua acontece en el texto como sujeto eclipsado en tanto es, a su vez, dominante y oprimida por los otros: "La yo tremenda, La volada, La feroz monja / La que abrió la boca y me la copiaron / Y la papa, de la que todos chupan / Pero está bien, pasen, pasen prelados" (Maquieira 2003: 44). En 
otras palabras, es también una lengua prostituida, ultrajada, deshonrada por el mismo sujeto fragmentario, en su intento por sobrevivir al desplome que él mismo constituye.

A pesar de su doble cariz, la imposición de esta lengua extranjera, española y hegemónica, condiciona la herencia cultural recibida por el sujeto oprimido, el que finalmente cede a la imposición por motivos de sobrevivencia $-\mathrm{o}$ amorosos, como sucedió con la indígena cuzqueña-: "La Tirana es también una dominadora en cuanto hereda una lengua y una tradición que ha expoliado a otras" (Brito 1994: 100). En ambos poemarios, el sujeto marginal asume los códigos y tradiciones del sujeto opresor, la posición y, a su vez, la subordinación imperialista a favor de su propia supervivencia. En este contexto, la figura de La Tirana representa en sí misma la traición hacia sí y hacia el otro, vale decir, la tradición traicionada al recepcionar y asumir como suyos códigos ajenos, tal como acontece también con la figura de la Malinche, indígena y amante de Cortés que, al dominar las lenguas azteca y maya, colabora con el conquistador español como traductora, y es finalmente abandonada por éste una vez que deja de serle útil en su afán imperialista (Paz 1994: 94).

En la obra de Maquieira, La Tirana constituye la representación del sujeto latinoamericano que, al intentar defender sus tradiciones -o su propia existencia-, termina reemplazando sus propios códigos y lenguaje por los de la entidad extranjera, la voz del colonizador, tal como sucedió con la leyenda de la indígena cuzqueña. En este sentido, La Tirana no es tal, no es "tirana", sino que, por el contrario, es ella quien ha sido tiranizada, dominada y, por consiguiente, anulada por el otro, por la lengua del otro, quien, no obstante, se desintegra junto a ella: "Mi instructor fue el señor Velázquez / Diego Rodríguez de Silva y Velázquez / y él me enseñó a cantar una canción / Si quieren escucharla, se las puedo cantar / se llama raja / raja, me estoy volviendo loca, Raja" (Maquieira 2003: 82).

\section{El ESPACIO DEL CARNAVAL: CAOS E INTERPOSICIÓN DE IDENTIDADES}

El proceso de interposición y eclipse entre ambos sujetos se genera de modo congruente en el contexto del caos, el desorden y el exceso del carnaval -al estilo barroco-, condiciones que favorecen el intercambio y la tergiversación de identidades. La crítica coincide al destacar el carnaval como dimensión predominante en $L a$ Tirana (Galindo 2005), lo que a nuestro parecer se hace extensivo también para Los Sea-Harrier... de 1986, en tanto los sujetos superponen y revierten identidades en medio del montaje -la ilusión- y la algarabía.

Para Bajtín (1998: 15), la forma del carnaval constituye una instancia de liberación transitoria, en la cual tiene lugar la abolición de las relaciones jerárquicas, privilegios, reglas y tabúes que condicionan, limitan y determinan regularmente a los sujetos. Al interior del carnaval, se restituye la igualdad entre los individuos, destituyendo las diferencias socioculturales que los separan en pos de una "forma especial de contacto libre" entre los sujetos, según sostiene el autor. Es así como en la obra de Maquieira tienden a diluirse de igual forma las jerarquías entre los personajes, en tanto cada uno de ellos asume el rol del otro, se eclipsa, se transpone en el espacio de su otredad, generando la fusión, el encuentro y el desencuentro entre los mismos: "Yo, María Velázquez de Mussolini / el más pasado para la punta que hay acá / rezo una última plegaria / por el mama de la media mente / y me voy con una rabia infinita" (Maquieira 2003: 78). 
Si bien la noción de carnaval se vincula a la de montaje, espectáculo y exposición teatral -en Maquieira, asociado a la ilusión y el discurso falaz de la hegemonía y la religión-, Bajtín señala que este espacio desconoce igualmente las distinciones entre actor y espectador, escenario y tribuna, vale decir, se convierte en un espacio en el cual todo lugar es a la vez otro, donde, a la manera de Borges, "cualquier lugar es otro lugar" (1998: 79); un laberinto en el cual los sujetos se pierden y se encuentran simultáneamente:

Los espectadores no asisten al carnaval, sino que lo viven, ya que el carnaval está hecho para todo el pueblo. Durante el carnaval no hay otra vida que la del carnaval. Es imposible escapar, porque el carnaval no tiene ninguna frontera espacial. En el curso de la fiesta sólo puede vivirse de acuerdo a sus leyes, es decir de acuerdo a las leyes de la libertad (Bajtín 1998: 13).

Tanto en La Tirana como en la plaquette de 1986 se da lugar a un espacio de encuentro y desconcierto, a partir del cual cada uno de los sujetos se transmuta en el otro. Es “El Gallinero", poema central del poemario de 1983, metáfora de un país -y un continente- abusado y torturado durante el periodo de dictadura militar, y en el cual los sujetos dejan de ocupar su propio lugar. Chile es el "gallinero" en relación al pueblo como entidad débil, vulnerable, marginada; y también lo es en función del repliegue propio del sistema hegemónico, en cuanto genera una imposición fundada en la opresión, la violencia y la crueldad; es la instauración de un falso orden militar en las palabras de Brito: "en un mundo que rinde tributo al caos, al desorden, como contrapartida al simulado 'orden militar', 'orden civilizado', 'orden moral'” (1994: 101).

El carnaval es el espacio de la fractura, la fractura del orden y la liberación de los sujetos, pero también del montaje, de la ilusión del orden y del discurso. En definitiva, es un espacio de desmoronamiento del yo que intenta, paradojalmente, reencontrarse y reconocerse en él: "No parábamos nuestra alegría de bacanal, / Nuestro delirante cortejo de matanzas / Y desórdenes continuos / Allá abajo en el hoyo del mundo" (Maquieira 1986: s/p). El carnaval es también, paradojalmente, espacio de encierro: no es posible escapar de él en tanto no hay límites que reconozcan una dimensión de la otra. El "gallinero" de Maquieira es, a su vez, el lugar de la prisión, el manicomio, el convento, en el cual subsisten y perecen los personajes: “¿Cuánta vida les has dado al manicomio?" (Maquieira 2003: 54).

Siguiendo a Bajtín, en este espacio acontecen bufones y payasos como señal del espectáculo que trasciende la vida del escenario, permaneciendo en la frontera que articula realidad e idealidad: "Gritos, saltos y vueltas de carnero / de los epilépticos más rayados” (Maquieira 2003: 54). El espectáculo de la risa en el medioevo se entrelaza, asimismo, con los ritos y fiestas pagano-religiosas de la Antigüedad (Bajtín 1998: 14). En la obra de Maquieira, lo anterior se reconoce en la referencia a la fiesta de La Virgen del Carmen de La Tirana efectuada en el norte de Chile en homenaje a la virgen pagana, cuya figura surge a partir de la leyenda cuzqueña y del templo levantado por un sacerdote español en el Tamarugal, lugar en el cual fueron encontrados los restos de la joven indígena (Emmerich 2004: 10).

Por otro lado, la figura del carnaval se encuentra asociada a la estética del barroco, en función del exceso y su carácter contradictorio. La crítica ha considerado, en efecto, la poesía de Maquieira como una escritura barroca, en tanto convergen en ella 
una serie de elementos contrapuestos, desde la sintaxis, la lengua -contemporánea y colonial; aristócrata y vulgar-, la diversidad de personajes y sujetos, hasta los retazos y fragmentos provenientes de otras escrituras - como es el caso de Garcilaso, Lope de Aguirre, Fidel Fita, entre otros- y/o discursos audiovisuales -entre ellos 2001 Odisea del Espacio de Stanley Kubrick, y La Balada de Cable Hogue, de Sam Peckinpah-. La crítica ha destacado en Maquieira la figura de una especie de bricolage (Donoso 2007) o pastiche en razón de la diversidad de voces y subjetividades en ella convergentes, las que fueron reunidas por el autor "carnavalescamente para significar, de alguna manera, la intrínseca perversión del poder ejemplificado por la Inquisición y su igualdad con las marginalidades que lo desestabilizan" (Lihn 1997: 168).

En La Tirana es posible reconocer la presencia de una serie de sujetos que no son otra cosa que "máscaras que hablan en los poemas (...) 'rayados', polimorfos, que cambian de sexo y provocan a la sintaxis" (Lihn 1997: 169), los que en función de su descentramiento, inestabilidad y transmutación de roles, persisten del mismo modo en Los Sea-Harrier .... Es así como el "comportamiento barroco", referido en el nombre del poema que inaugura la plaquette, "Baroque Behavior", en tanto marginal y contradictorio, opera como eje medular en la obra de Maquieira de acuerdo a las transposiciones y discordancias de identidades presentes $-\mathrm{y}$ ausentes- en los sujetos. En el arte barroco se visualiza la inestabilidad del principio de identidad, debido a que el sujeto está condicionado a un estado de mudanza permanente, de cambios incesantes, tal como expone Maravall: "En el cambio mismo se apoya la permanencia de las cosas: su mutabilidad es la razón de su subsistencia" (Cit. en Foxley 1995: 28).

La contradicción constituye un elemento constitutivo de esta estética, en cuyas producciones artísticas tienden a confluir, por lo general, fenómenos de naturalezas opuestas, dando origen a situaciones escindidas, disímiles, heterogéneas, tal como sucede en la sincrética Fiesta de La Tirana, en la cual desemboca la antinomia entre lo mundano y el espíritu, propio del sentimiento barroco: “... el hombre es un animal religioso. Como animal irrumpe en fuerzas contenidas, en pasión, vida, movimiento, impulso hacia arriba y hacia abajo, características de las formas de expresión barrocas. Como religioso se lanza hacia lo alto, con un impulso ascendente de fe, que no consigue desligarse de los apetitos terrenos", arguye García Morejón (Cit. en Aguiar e Silva 1975: 285). En la obra de Maquieira, la contradicción y exhuberancia barroca acontecen en la oposición dispuesta por los sujetos dominantes y dominados, que a su vez guardan en sí mismos esa propia dualidad, dando cuenta de ello por medio de la multiplicidad de voces e identidades que se interceptan, interactúan y distancian al interior de los textos: sujetos multiformes, escindidos, duales e interpuestos, eclipsados, a causa de la misma fragmentación que representan.

En términos derridianos, esta oposición entre los sujetos -opresor y oprimido-y su respectiva dualidad se diluyen, pues el sentido de una entidad está contenido a su vez en la otra. No existe unicidad en sí mismas, sino que cada una de ellas conlleva la esencia de su propia alteridad. La noción de differance reconoce la fisura en la entidad discursiva, posibilitando el desplazamiento de fronteras y la apertura hacia otra alteridad semántica: la differance, según Derrida, concebida como un "juego sistemático de diferencias, de huellas de diferencias, del ordenamiento (espacement) por el que los elementos se relacionan unos con otros" (Cit. en Culler 1992: 89). Las huellas de la dualidad se accionan dejando en evidencia el juego de presencias / ausencias existente en las configuraciones subjetivas de cada entidad. 
Lo anterior responde a un proceso de inversión de jerarquías a través del cual se desestabilizan finalmente ambas estructuras: la del sujeto de poder, el tirano, y la del sujeto subyugado, marginal. Es así como en la obra de Maquieira los sujetos se perturban y desmoronan en el vínculo establecido tanto consigo mismo como con los otros, sujetos que "pensando y dándole vueltas a la Derrida" (Maquieira 2003: 54) se desarticulan al coincidir "en el firmamento de eclipses" -sintagma suprimido por el autor en el título de la versión definitiva de 1993-, un firmamento que, en razón de los encuentros que cobija entre entidades precarias, transpuestas y eclipsadas, pierde sustento, se desmorona, revelando su verdadera condición: una ilusión, un montaje, un escenario en proceso de desintegración.

\section{OBRAS CITADAS}

Aguiar e Silva, Vítor Manuel. 1975. Teoría de la literatura. Madrid: Gredos.

Bajtín, Mijaíl. 1998. La cultura popular en la Edad Media y en el Renacimiento: El contexto de Francois Rabelais. Madrid: Alianza.

Berman, Marshall. 1997. Todo lo sólido se desvanece en el aire. Madrid: Siglo XXI.

Brito, Eugenia. 1985. "'La Tirana', de Diego Maquieira. Lectura y análisis”. Pluma y Pincel 16: 44-46.

. 1994. "La Tirana, de Diego Maquieira. Una misa negra en la literatura chilena". En Brito, Eugenia, Campos minados. Literatura post-golpe en Chile. Santiago: Cuarto Propio. 95-110.

Borges, Jorge Luis. 1998. El Aleph. Madrid: Alianza.

Culler, Jonathan. 1992. Sobre la deconstrucción. Madrid: Cátedra.

Dussel, Enrique. 1992. 1492. El encubrimiento del otro. Hacia el origen del "mito de la modernidad". Santafé de Bogotá: Ediciones Antropos.

Donoso, Arnaldo Enrique. 2007. "Tirana (1983), de Diego Maquieira. Mestizaje, ficcionalización y referencialidad anómala. Devenir gramático de la opsys”. Recuperado de http:// www.letras.s5.com/aed130407.htm

Emmerich, Fernando. 2004. Leyendas chilenas. Santiago: Pehuén Editores.

Foucault, Michel. 1999. Estética, ética y hermenéutica. Obras esenciales. Volumen III. Barcelona: Paidós.

2005. Vigilar y castigar. Nacimiento de la prisión. Buenos Aires: Siglo XXI.

2006. Las palabras y las cosas. Una arqueología de las ciencias humanas. Madrid: Siglo XXI.

Fornet-Betancourt, Raúl. 2000. Interculturalidad y globalización. Ejercicios de crítica filosófica intercultural en el contexto de la globalización neoliberal. San José: DEI.

Foxley, Carmen. 1995. Enrique Lihn: Escritura excéntrica y modernidad. Santiago: Universitaria.

Gadamer, Hans-Georg. 1992. Verdad y Método II. Salamanca: Ediciones Sígueme.

Galindo, Oscar. 2003. "Autoritarismo, enajenación y locura en la poesía chilena de fines del siglo XX. Zurita, Maquieira, Cuevas". América Latina Hoy 30: 97-118. 2005. "Neomanierismo, minimalismo y neobarroco en la poesía chilena contemporánea". Estudios Filológicos 40: 79-94.

Gergen, Kenneth. 1996. Realidades y relaciones: Aproximaciones a la construcción social. Barcelona: Paidós.

Harris Espinosa, Tomás. 2003. "La Virgen en el Santuario Desmoronado (sobre 'La Tirana' de Diego Maquieira". Revista Mapocho 54: 105-114.

Hidalgo, Patricio y Daniel Hopenhayn. 2008. Give me break. Conversaciones con Diego Maquieira. Santiago: Universitaria. 
Krysinski, Wladimir. 1993. “'Subjectum comparationis': Las incidencias del sujeto en el discurso”. En Angenot, Marc et al. (Dirs.), Teoría literaria. México D.F.: Siglo XXI. 270286.

Lihn, Enrique. 1997. El circo en llamas. Santiago: LOM.

Maquieira, Diego. 1986. Los Sea-Harrier en el firmamento de eclipses. Poemas de Anticipo. Santiago: Francisco Zegers Editor. . 2003. La Tirana. Santiago: Tajamar Ediciones.

Mignolo, Walter (Comp.). 2001. Capitalismo y geopolitica del conocimiento. Buenos Aires: Ediciones del Signo.

Paz, Octavio. 1994. El laberinto de la soledad. Postdata. Vuelta al laberinto de la soledad. México D.F.: Fondo de Cultura Económica.

Peralta, Ramón. 2006. "El sentido de historia en 'Los Sea Harrier'”. Recuperado de http:// www.letras.s5.com/dm070306.htm

RAE. 2003. Diccionario de la Real Academia Española. Recuperado de http://www.rae.es/

Ricoeur, Paul. 2003. Si mismo como otro. México D.F.: Siglo XXI.

Roa, Armando. 1995. Modernidad y posmodernidad. Coincidencias y diferencias fundamentales. Santiago: Andrés Bello.

Schopf, Federico. 1987. "Lenguaje ajeno". El Organillo: Poesía y cuento 9: 14-15. 